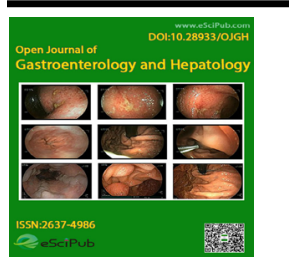

\title{
Open Journal of Gastroenterology and Hepatology
}

(ISSN:2637-4986)

\section{Usefulness of Castor Oil and Elobixibat and Lactulose and ascorbic Aid for Bowel Preparation for Colon Capsule Endoscopy-Initial examination}

\section{Naoki Hotta}

Department of Internal Medicine, Division of Gastroenterology, Masuko Memorial Hospital, Aichi, Japan.

\begin{abstract}
Colon capsule endoscopy was approved for reimbursement *Correspondence to Author: under the national health insurance system of Japan in 2014.

Dr. Naoki Hotta

However, the capsule excretion rate after recommended

Department of Internal Medicine, bowel preparation reportedly ranges from $70 \%$ to $90 \%$, and Division of Gastroenterology, Masuadministration of boosters is also necessary. The caster oilko Memorail Hospital, Aichi, Japan. based booster had an emission rate of 97\%, but required a Telephone: Japan 81-52-451-1465 total water content of $3 \mathrm{~L}$. Considering whether it is possible to Facsimile: Japan 81-52-451-1360 popularize colon capsule endoscopy by reducing the amount of water, including dialysis patients with water restrictions, we will consider whether the capsule discharge rate can be improved by How to cite this article: combining new laxatives.

Naoki Hotta. Usefulness of Castor Oil and Elobixibat and Lactulose and ascorbic Aid for Bowel Prepar-

Keywords: Castor Oil; Elobixibat; Ascorbic Aid; Colon Capsule Endoscopy ation for Colon Capsule EndoscopyInitial examination.Open Journal of Gastroenterology and Hepatology, 2021; 4:42.

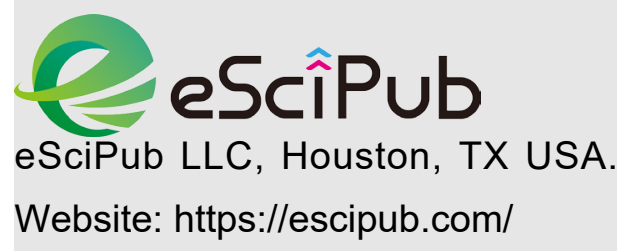




\section{Introduction}

The incidence and prevalence of end stage renal disease (ESRD) have been increasing worldwide. A previous study reported that ESRD patients tend to have various gastrointestinal lisions and associated complication [1]. In addition,the incidence of vascular lesions such as angioectasia has also been reported to be increases in these patients ${ }^{[2,3,4]}$. Colon capsule endoscopy $[5,6,7]$ was approved for reimbursement under the national health insurance system of Japan in 2014. However, the capsule excretion rate after recommended bowel preparation reportedly ranges from $70 \%$ to $90 \%$, and administration of boosters is also necessary. For dialysis patients, liquid loading is a problem. At our hospital, the capsule excretion rate after recommended bowel preparation was $53 \%$ in dialysis patients ${ }^{[8]}$. However, we examined a defecation desire by five cases that was not a patient on dialysis this time while we dialyzed it when the patient on dialysis took a point and the laxative with moisture restrictions on the day before dialysis to hate quitting a thing.

\begin{tabular}{|c|c|c|c|c|}
\hline \multirow{5}{*}{$\begin{array}{l}\text { Day } \\
\text { before } \\
\text { endoscopy }\end{array}$} & 2 day before endoscopy & \multicolumn{2}{|c|}{ movical2T lactulose $15 \mathrm{ml}$} & \multirow[b]{2}{*}{$\begin{array}{l}\text { Liquid } \\
\text { volume }\end{array}$} \\
\hline & Time & Procedure & Regimen & \\
\hline & Morning, noon, and evening & $\begin{array}{l}\text { Low-residue } \\
\text { diet }\end{array}$ & Enimaclin movical2 $\mathrm{T}$ lactulose $15 \mathrm{ml}$ each time & \\
\hline & 21:00 & $\begin{array}{l}\text { Bowel } \\
\text { cleansing }\end{array}$ & $\begin{array}{l}\text { Picosulfate sodium: } 1 \text { packet } \\
\text { Elobixibate: } 2 \text { tablets }\end{array}$ & - \\
\hline & After 21:00 & & Fasting & \\
\hline
\end{tabular}

\begin{tabular}{|c|c|c|c|c|c|}
\hline \multirow[t]{7}{*}{$\begin{array}{l}\text { Day of } \\
\text { endoscopy }\end{array}$} & Time & Procedure & Regimen & $\begin{array}{l}\text { Liquid } \\
\text { volume }\end{array}$ & total \\
\hline & 9:00-11:00 & $\begin{array}{l}\text { Bowel } \\
\text { cleansing }\end{array}$ & $\begin{array}{l}\text { Moviprep (containing Gascon Drop): } 0.25 \mathrm{~L}+\text { water } \\
\text { (or tea): } 0.125 \mathrm{~L}\end{array}$ & $0.25 \mathrm{~L}$ & $0.375 \mathrm{~L}$ \\
\hline & Capsule ingestion & & $\begin{array}{l}\text { Ingest a capsule endoscope with Gascon: } 4 \mathrm{~mL}+ \\
\text { water: } 0.1 \mathrm{~L}\end{array}$ & - & $0.475 \mathrm{~L}$ \\
\hline & $\begin{array}{l}\text { Immediately after capsule } \\
\text { ingestion }\end{array}$ & & $\begin{array}{l}\text { Castor oil: } 30 \mathrm{~mL} \text {, Lactulose } 15 \mathrm{ml} \text { intramuscular } \\
\text { injection of metoclopramide }\end{array}$ & - & - \\
\hline & $\begin{array}{l}\text { After the capsule reaches the } \\
\text { small intestine }\end{array}$ & $\begin{array}{l}\text { Confirming the } \\
\text { arrival } \\
\text { Enhancing } \\
\text { peristalsis }\end{array}$ & $\begin{array}{l}\text { No water intake but hard candy and gum is allowed } \\
\text { until the capsule endoscope reaches the small } \\
\text { intestine. Oral administration of mosapride: } 4 \text { tablets. } \\
\text { Moviprep: } 0.25 \mathrm{~L} \text { + water (or tea): } 0.125 \mathrm{~L}\end{array}$ & $0.25 \mathrm{~L}$ & $.085 \mathrm{~L}$ \\
\hline & 1 hour later & Booster & $\begin{array}{l}\text { Castor oil: } 30 \mathrm{~mL} \text {, Lactulose } 15 \mathrm{ml} \text { Teleminsoft } \\
\text { suppository, Moviprep: } 0.25 \mathrm{~L}+\text { water (or tea): } \\
0.125 \mathrm{~L}\end{array}$ & $0.25 \mathrm{~L}$ & $1.225 \mathrm{~L}$ \\
\hline & 2 hours later & Booster & $\begin{array}{l}\text { Mosapride: } 6 \text { tablets, Magcorol P: } 1 \text { package }+ \\
\text { water: } 0.45 \mathrm{~L} \text {. * Dialysis patients: Oral } \\
\text { administration of castor oil: } 30 \mathrm{~mL} \text {. Glycerol enema } \\
\text { at } 15: 30 \text {. }\end{array}$ & $0.45 \mathrm{~L}$ & $1.675 \mathrm{~L}$ \\
\hline
\end{tabular}

\section{Methods and Patients}

This study 5 patients who underwent colon capsule endoscopy at Masuko Memorial Hospitalsince March 2020. The5 patients (3 men and 2 women. With mean age of 49 years, All enrolled patients were informed of the risks and complications Colon Capsule, such as capsule retrntion.Written informed consent was obtained 
from all patients.Colon capsule endoscopy was performed with PillCam COLON Capsule (Medtronic, Minneapolis, MN, USA). The recommended protocol of bowel preparation was modified (with adminis-tration of Elobixibat and Lactulosef), and success rates of completing entire colon observation were compared. The modified regimen is shown in

\section{Table 1.}

This protocol is a few improvements over the one announced in $2020^{[9]}$. One was to take $15 \mathrm{ml}$ of lactulose and 2 packs of Mobicol 2 days before the test to confirm the discharge of stool. In the morning and noon the day before the test, we decided to have them take $15 \mathrm{ml}$ of lactulose and 2 packets of mobicol, $2 \mathrm{~T}$ of goofis before dinner, $15 \mathrm{ml}$ of lactulose and 2 packets of mobicol after dinner, and 1 packet of laxoberon before bedtime.

\section{Results}

The success rate was $100 \%(5 / 5)$.

The average water intake was $1422 \mathrm{ml}$ (800$2225 \mathrm{ml}$ ), which could be reduced compared to the conventional protocol. Colon transit time averaged 142.4 minutes (54-408 minutes).

\section{Discussion}

Only one case examined this time had a history of abdominal surgery, but the capsule discharge rate was as short as 54 minutes. In the case where it took 408 minutes to drain, there was an episode that there was adhesion when colonoscopy was performed before, and it took a long time for colonoscopy at that time. Since the capsule was actually retained in the sigmoid colon for a long time, it was considered that the adhesion took a long time. This protocol was able to decrease shortening of the discharge time and the fluid intake than our previous report, too. The moisture stops drinking when it egested a capsule. Fewest cases were $580 \mathrm{ml}$ this time. Lactulose was a drug for hepatic encephalopathy, but also indicated additional indications for constipation. By taking this medicine and castor oil at the same time, The bitterness of castor oil could be masked. Elobixibit is a novel ileal bild acid transportor inhibitor that is expressed in the terminal ileum for treatment of chonic constipation ${ }^{[9]}$. When the disease or resection, excessive quantities of bile acids many enter colon, thereby resulting in diarrhea [11]. By these effects, activity of the bowel movement improved, and a capsule discharge rate was thought to improve even few fluid volumes. The examination of our castor oil showed a $100 \%$ discharge rate. The capsule transit time after bowel preparation with Elobixibat and lactulose was shortened, and the booster dosage was also reduced. $\mathrm{n}$ a change of the protocol, we used movicol and lactulose from a day in examination far in advance. There was not the history of the constipation with neither five people who examined it this time and did not show taking laxative either. We thought that it might become possible to reduce a fluid volume by reducing a stool residue on the day of the examination and changed the protocol. As a result, we succeeded in reducing discharge time and the fluid volume.

This time, Protocol is difficult to use for dialysis patients. This is because laxatives are used from 2 days before treatment, so there is a high possibility that they will feel sick during dialysis. 
Dialysis patients are reluctant to go to stool during dialysis. Therefore, this protocol is very useful for non-dialysis patients.

\section{Conclusion}

In future studies, it is necessary to consider a booster that can evaluate polyps and inflammation with a high degree of colon cleansing in order to further reduce the amount of water, and for non-dialysis patients, the number of patients by the current method It is considered necessary to increase and consider it.

\section{Refernces}

[1] US Renal Data System USRDS,2011 Annual Data Report:Atlas of Chronic Kidney Disease and End-Stage Renal Disease in the United States,National Insitue of Health,National Institute of Diabetes and Digestive and Kidney Diseases,Bethesda,Md,USA,2011

[2] Kang JY.The gastrointetestinal tract in uremia.Dig Dis Sic 1993;38:257-258

[3] Etemad B.Gastrointestinal complications of renal failure.Gastroenterogy clinics of North Amarica 1998:27;875-892

[4] N Hosoe,S Matsukawa,Y kanno et al. Crosssectional small intestinal surveillance of maintence hemodialysis patients using vido capsule endoscopy:SCHEMA study.Endoscopy
International Open2016;04:E589-E596

[5] Tajiri H.Current Situation And Problems Of Colon Capsule Endoscopy.Gastroenteroligical Endoscopy.(2011) ;Vol53(9)SEP :2998-2999

[6] Simon Bouchard,Mostafa Ibrahim,Andre Van Gossum.Video capsule endoscopy:Perspectoves of a revolutionary technique.World J of Gastroenterology 2014; volume20:17330-17343

[7] Yasuo Kakugawa,Yutaka Saito,Shoichi Sato et al;New reduced volume preparation regimen in colon capsule endoscopy. World $\mathrm{J}$ of Gastroenterology 2012;volume18:2092-2098

[8] Naoki Hotta.The Use of Castor Oil for Bowel Preparation for Colon Capsule Endoscopy.Open Journal of Medical Imaging 2016:,6:103-107

[9] Gillberg, P.G., Dahlstrom, M., Starke, I., et al. (2010) The IBAT Inhibition by A3309-A Potential Mechanism for the Treatment of Constipation. Gastroenterlo-gy, 138, S-224

[10] Naoki Hotta.Usefulness of castor oil and elobixibat and lactulose and ascorbic aid for Bowel preparation for colon capsule endoscopy;A case report 2020 OIGH 3:31

[11] Iser, J.H. and Sali, A. (1981) Chenodeoxycholic Acid: A Review of Its Pharmacolog-ical Properties and Therapeutic Use. Drugs, 21, 90119. 